\title{
QUALITY IMPROVEMENT OF PLASTIC INJECTION Molded Product Using DoE ANd TAguChi TECHNIQUES
}

\author{
Varun Sharma ${ }^{1}$,Ashish Goyal ${ }^{1}$, Sanjay Kumar Sharma ${ }^{2}$, Vikas Sharma ${ }^{2}$ \\ ${ }^{1}$ Manufacturing Engineering Department, Manipal University, Jaipur, Rajasthan, India \\ ${ }^{2}$ Design Engineer, Grob Design Pvt. Ltd., Jaipur, Rajasthan, India
}

\begin{abstract}
This paper studies the effect of process parameters like melt temperature, mold temperature,packing pressure, sprue diameter and gate diameter on product quality responses like fill time of cavity and volumetric shrinkage of electrical switch board.In the first part an experimental methodology was developed using DOE (Design of experiment)technique. Taguchi method was used to design an orthogonal array of five factors having three levels. Second part is developing FEM simulation using MFA software provided by Autodesk Company. Main results are based on S/N ratio and ANOVA analysis. It is found that most critical parameter in this study is sprue diameter and less effective parameter is packing pressure. Model equations are also developed in this study.
\end{abstract}

\section{KEYWORDS}

MFA, DOE, taguchi methods, ANOVA, Model Equations

\section{INTRODUCTION}

Plastic injection molding is a common process in most of the plastic parts while a plastic injection mold, whose design is an integral part of plastic injection molding, is a high precision tool for the mass production of plastic parts in the industries like electronics, automotive and medical sector and so on. This process required expensive tools and machinery in manufacturing. There are two main components that are required in plastic injection molding. The one is plastic injectionmolding machine and another is injection mold. The mold is mounted on the plastic injectionmolding machine then the molten plastic was injected into the mold maintaining a sufficient pressure and allows it to solidify in the mold. On the other hand, the injection mold is a tool for transforming the molten plastic into the final shape and dimensions of the plastic part. In the present scenario high technologies are needed to satisfy the consumer demands. At present mostly design, manufacturing and testing of plastic parts are done by using experience of the mold designersand other personnel. Although some standardization had been introduces in the mold making industries to design mold, but still most of the design process was done on the experience of personnel. The plastic industry is growing faster replacing the several traditional materials in every industry due to properties like strength-to-weight ratio, higher production rates, corrosion resistances, design flexibility, electrical insulator and easy to recycle. For example: transportation and other industries used fibre glass structure due to their strength-to weight ratio and flexibility in design property. Due to corrosion resistant property of glass fibre reinforced plastic storage tanks and supply pipes were also manufactured by it. 


\section{Numerical Simulation}

Autodesk Simulation Moldflow (2014), MFA is a complete suite of definitive tools for simulating, analyzing, optimizing and validating plastics part and mold designs in plastics injection molding. MFA address the broadest range of manufacturing issues and design geometry types associated with plastics molding processes. Thus, MFA can work to reduce or eliminate time delays, improve part quality, and deliver projects within budget constraints. With MFA analysis modules, filling, packing, and cooling stages of the plastic, the injection molding process can be simulated. MFA also predict post-molding phenomena such as shrinkage sink mark, air trap, weld line, and war page of the products. In addition, MFA offers an expanded material database, which includes over 9300 unique plastic materials for use in plastic injection molding process simulation software in order to ensure that users have access to the highest quality material data for plastic simulation.

\section{STEPS FOLLOW BY SOFTWARE}

Step 1: In the first step a CAD model was imported in mold flow software, which was created by using Auto-desk Inventor 2014.

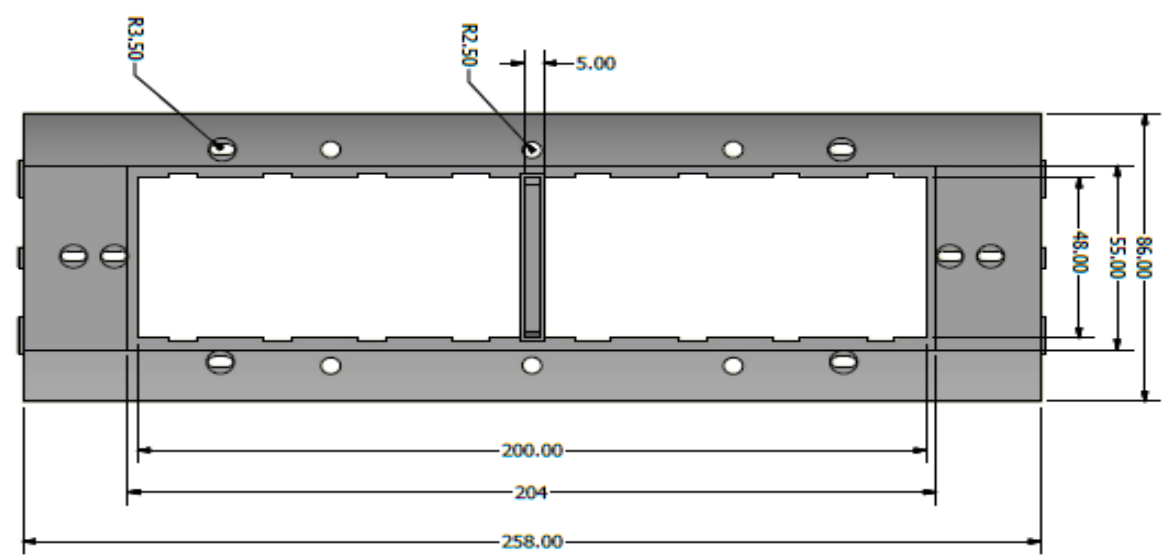

Fig. 1 CAD Geometry made by Autodesk Inventor

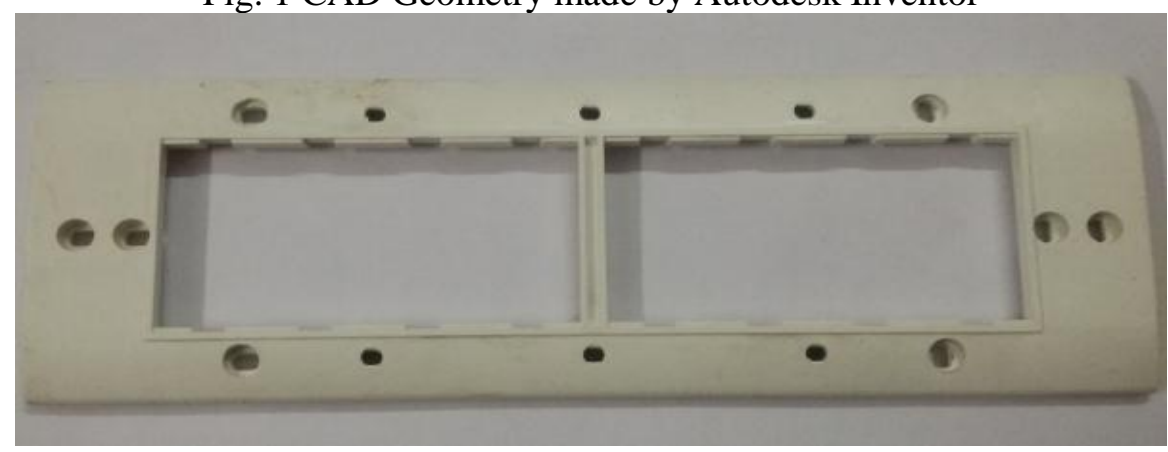

(a) 


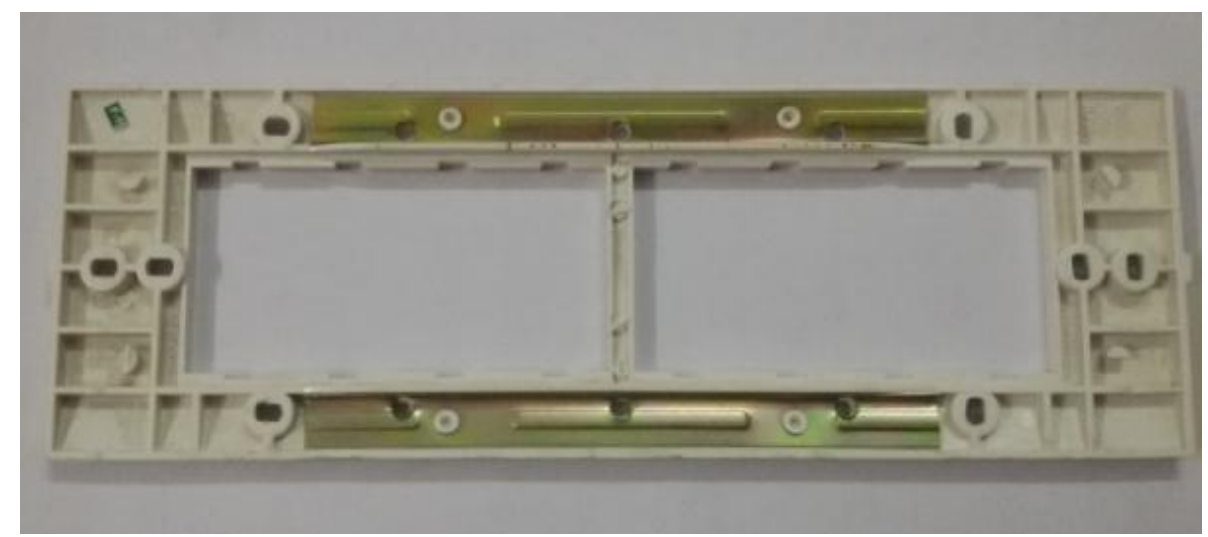

(b)

Fig. 2(a) Front view \& (b) Back view of original product

Step 2: Mesh the CAD model.

It is very easy to mesh in MFA software. It meshes automatically using triangular elements to cover the model surface with least distortion.

Step 3: Material Selection: -Taiwan PP

\begin{tabular}{|lcl|}
\hline \multicolumn{2}{|l|}{ Specification of the moulding material } & \\
\hline Manufacturer & $:$ & Taiwan PP \\
\hline Trade Name & $:$ & Globalene 6331 \\
\hline Family Abbreviation & $:$ & PP \\
\hline Density & $:$ & $0.7751 \mathrm{~g} / \mathrm{cm}^{3}$ \\
\hline Process Temperature & $:$ & $200-280{ }^{\circ} \mathrm{C}$ \\
\hline Mold Temperature $\quad:$ & $20-80{ }^{\circ} \mathrm{C}$ & \\
\hline
\end{tabular}

Step 4: Process parameters selection
1. Melt Temperature
2. Mold Temperature
3. Packing Pressure
4. Sprue diameter

5. Gate diameter

Step 5: Results

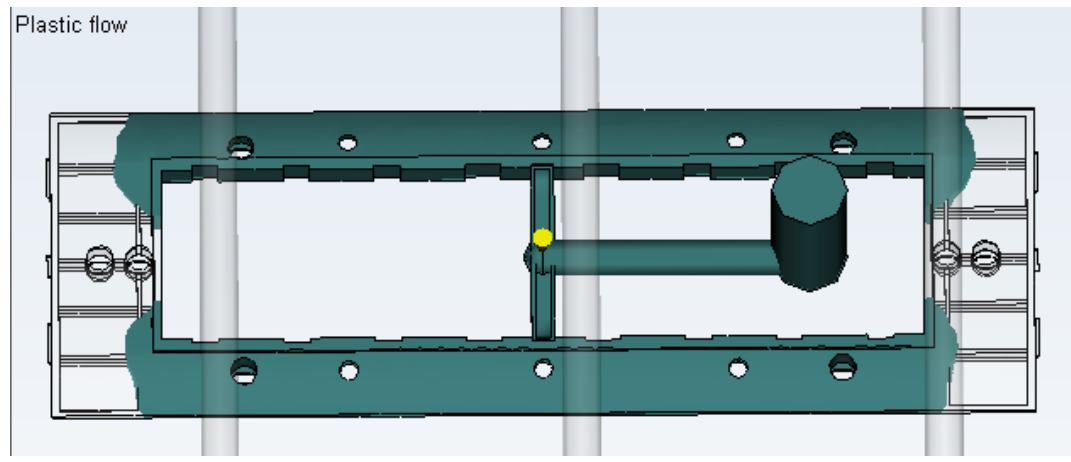

Fig. 3 Cavity FillingProcess 


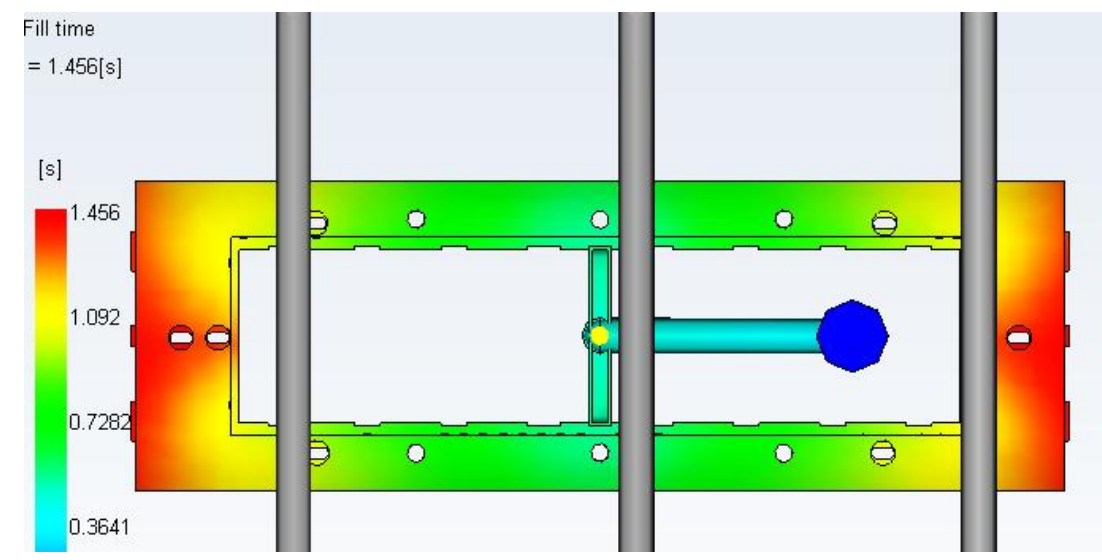

Fig. 4 Fill Time

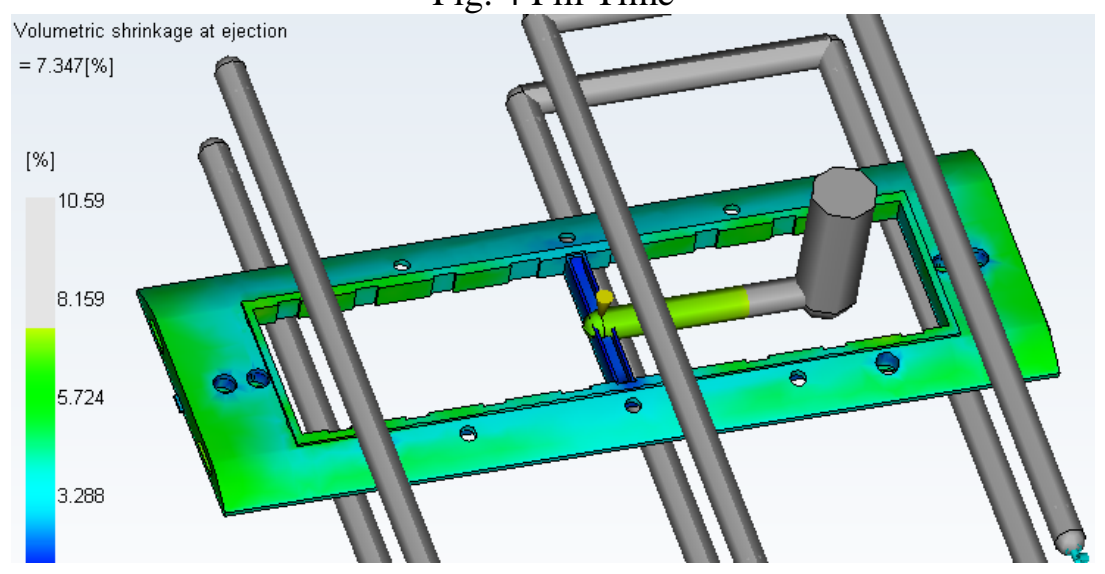

Fig. 5 Volumetric Shrinkage

\section{Problem Description}

The problem focused in this study was to apply CAE methods in plastic injection molding process to improve productivity of thick plastic products. In this study five controlling factors named mold temperature, melt temperature, packing pressure, sprue diameter and gate diameter were used with their levels and taguchi tables were used for design of experiment.

\section{DESIGN OF EXPERIMENT METHODOLOGY}

The quality of product made from plastic injection molding process is always depends on its process parameters like injection pressure, cooling time, injection speed, packing pressure, mold temperature, melt temperature, gate diameter, packing time, and many more. Lot of researchers studies the effect of these factors on the quality of plastic parts. DESIGN OF EXPERIMENT approach is very helpful to researchers in designing an experiment for any type of research.This technique was adopted by researcher for this study. By using DOE techniques any researcher can determine important factors which are responsible for output result variation of experiments. DOE can found optimum solution for particular experiments. 
International Journal of Recent advances in Mechanical Engineering (IJMECH) Vol.4, No.2, May 2015

\section{FACTORS AND LEVELS}

By the selection of proper factors and their levels design of DOE table was only done. In this paper five factors with three levels were selected for product and were shown in table 1 .

Table 1 Summary table of Factors and Levels for used product

\begin{tabular}{|c|c|c|c|c|c|}
\hline Level & $\begin{array}{c}\text { Melt } \\
\text { Temp. } \text { in } \\
{ }^{\mathbf{C}} \mathbf{C}\end{array}$ & $\begin{array}{c}\text { Mold Temp. } \\
\text { in }^{\mathbf{}} \mathbf{C}\end{array}$ & $\begin{array}{c}\text { Packing Pr. In } \\
\mathbf{M P a}\end{array}$ & $\begin{array}{c}\text { Sprue Dia. In } \\
\mathbf{~ m m}\end{array}$ & $\begin{array}{c}\text { Gate Dia. } \\
\text { In mm }\end{array}$ \\
\hline 1 & 225 & 45 & 90 & 16 & 8 \\
\hline 2 & 230 & 50 & 95 & 18 & 9 \\
\hline 3 & 235 & 55 & 100 & 20 & 10 \\
\hline
\end{tabular}

Orthogonal Array

\begin{tabular}{|c|c|c|c|c|c|c|c|}
\hline $\begin{array}{c}\text { Sr. } \\
\text { No. }\end{array}$ & $\begin{array}{c}\text { Melt } \\
\text { Temp.(C) }\end{array}$ & $\begin{array}{c}\text { Mold } \\
\text { Temp.(C) }\end{array}$ & $\begin{array}{c}\text { Packing } \\
\text { Pr.(MPa) }\end{array}$ & $\begin{array}{c}\text { sprue } \\
\text { Dia.(mm) }\end{array}$ & $\begin{array}{c}\text { Gate } \\
\text { Dia.(mm) }\end{array}$ & $\begin{array}{c}\text { Fill } \\
\text { Time } \\
(\mathbf{s e c})\end{array}$ & $\begin{array}{c}\text { Volumetric. } \\
\text { Shrinkage } \\
\text { (\%) }\end{array}$ \\
\hline 1 & 225 & 45 & 90 & 20 & 10 & 1.456 & 7.347 \\
\hline 2 & 225 & 45 & 90 & 20 & 9 & 1.412 & 7.497 \\
\hline 3 & 225 & 45 & 90 & 20 & 8 & 1.417 & 7.293 \\
\hline 4 & 225 & 50 & 95 & 18 & 10 & 1.407 & 7.59 \\
\hline 5 & 225 & 50 & 95 & 18 & 9 & 1.381 & 7.557 \\
\hline 6 & 225 & 50 & 95 & 18 & 8 & 1.361 & 7.511 \\
\hline 7 & 225 & 55 & 100 & 16 & 10 & 1.355 & 7.38 \\
\hline 8 & 225 & 55 & 100 & 16 & 9 & 1.337 & 7.347 \\
\hline 9 & 225 & 55 & 100 & 16 & 8 & 1.309 & 7.303 \\
\hline 10 & 230 & 45 & 95 & 16 & 10 & 1.225 & 7.288 \\
\hline 11 & 230 & 45 & 95 & 16 & 9 & 1.21 & 7.27 \\
\hline 12 & 230 & 45 & 95 & 16 & 8 & 1.184 & 7.229 \\
\hline 13 & 230 & 50 & 100 & 20 & 10 & 1.455 & 7.569 \\
\hline 14 & 230 & 50 & 100 & 20 & 9 & 1.433 & 7.534 \\
\hline 15 & 230 & 50 & 100 & 20 & 8 & 1.414 & 7.489 \\
\hline 16 & 230 & 55 & 90 & 18 & 10 & 1.412 & 7.595 \\
\hline 17 & 230 & 55 & 90 & 18 & 9 & 1.387 & 7.564 \\
\hline 18 & 230 & 55 & 90 & 18 & 8 & 1.366 & 7.523 \\
\hline 19 & 235 & 45 & 100 & 18 & 10 & 1.27 & 7.315 \\
\hline 20 & 235 & 45 & 100 & 18 & 9 & 1.412 & 7.497 \\
\hline 21 & 235 & 45 & 100 & 18 & 8 & 1.247 & 7.301 \\
\hline 22 & 235 & 50 & 90 & 16 & 10 & 1.227 & 7.302 \\
\hline 23 & 235 & 50 & 90 & 16 & 9 & 1.214 & 7.273 \\
\hline 24 & 235 & 50 & 90 & 16 & 8 & 1.187 & 7.234 \\
\hline 25 & 235 & 55 & 95 & 20 & 10 & 1.312 & 7.54 \\
\hline 26 & 235 & 55 & 95 & 20 & 9 & 1.292 & 7.523 \\
\hline 27 & 235 & 55 & 95 & 20 & 8 & 1.277 & 7.479 \\
\hline & & & & & & & \\
\hline
\end{tabular}


Outcome parameters for this study were fill time (sec) and volumetric shrinkage (\%) After selection of factors and levels for current study it was important to select accurate orthogonal array and for this task MINITAB software was used for making of orthogonal array of factors and their levels.

\section{RESULT AND DISCUSSION}

Single cavity plastic injection molding process was simulated in this study for electrical switch board. Autodesk mold flow adviser ultimate FEM package was used for simulation purpose. And the experiment was designed using DOE technique in which a Taguchi orthogonal array table was created, which was discussed in table 2. Main outcomes focused in this were following:

\section{Fill Time}

\section{Volumetric Shrinkage}

Analysis of variance (ANOVA)

$\mathrm{S} / \mathrm{N}$ Ratio (signal to noise ratio)was used to find out the effect of changing of factors according their levels on product quality. The outcome parameters of this study are fill time and volumetric shrinkage both of them should be small as possible for good quality so "smaller is better" approach was taken as quality indicator for $\mathrm{S} / \mathrm{N}$ ratio.

The response tables for design case was shown in table $3 . \mathrm{S} / \mathrm{N}$ ratio gives best combination of input parameters for case.

Table 3 The response table for $\mathrm{S} / \mathrm{N}$ ratio

\begin{tabular}{|c|c|c|c|c|c|}
\hline Level & $\begin{array}{c}\text { Mold } \\
\text { Temp. }\end{array}$ & Melt Temp & Packing Pr. & Sprue dia. & Gate dia. \\
\hline 1 & -14.44 & -14.55 & -14.52 & -14.37 & -14.48 \\
\hline 2 & -14.57 & -14.57 & -14.55 & -14.62 & -14.57 \\
\hline 3 & -14.60 & -14.48 & -14.53 & -14.61 & -14.56 \\
\hline Delta & 0.16 & 0.09 & 0.04 & 0.25 & 0.10 \\
\hline Rank & 2 & 4 & 5 & 1 & 3 \\
\hline
\end{tabular}

Response table for plastic product were show that input Parameter sprue diameter, was most critical responsible parameter for shrinkage and fill time outcomes. Rank was also show based on response table. Most critical parameter was sprue diameter whereas less important parameter was packing pressure because level values were high and show no effect in product quality variation. Figure 6shows graphical presentation of $\mathrm{S} / \mathrm{N}$ ration and also show best cases for all experiments.

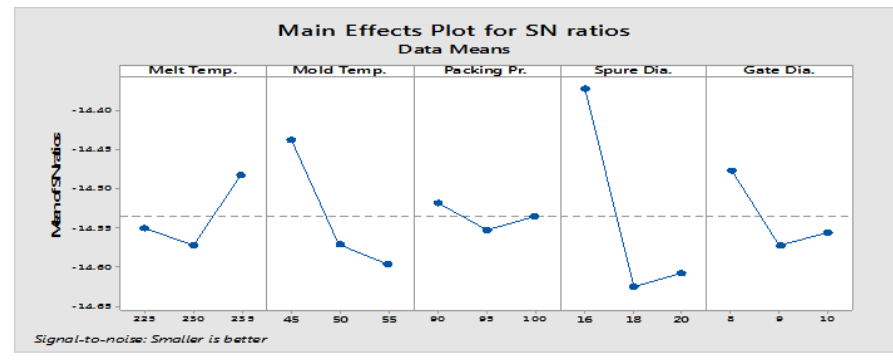

Fig. $6 \mathrm{~S} / \mathrm{N}$ ratio 
$\mathrm{S} / \mathrm{N}$ ratio was good approach to find optimum combination of input parameters which is shown in the table no. 4.

Table 4The optimum combination of parameters

\begin{tabular}{|c|c|c|c|c|c|}
\hline Case & $\begin{array}{c}\text { Melt } \\
\text { Temp. in } \\
\mathbf{}^{\mathbf{C}}\end{array}$ & $\begin{array}{c}\text { Mold Temp. } \\
\text { in }{ }^{\mathbf{0}} \mathbf{C}\end{array}$ & $\begin{array}{c}\text { Packing Pr. In } \\
\mathbf{M P a}\end{array}$ & $\begin{array}{c}\text { Sprue Dia. In } \\
\mathbf{~ m m}\end{array}$ & $\begin{array}{c}\text { Gate Dia. } \\
\text { In mm }\end{array}$ \\
\hline Best & 235 & 45 & 90 & 16 & 8 \\
\hline Worse & 230 & 55 & 95 & 18 & 9 \\
\hline
\end{tabular}

\subsection{ANOVA Analysis}

The analysis of variance was calculated for plastic product and results were shown in table 5 to table 6 respectively. In ANOVA analysis F-Test was conduct to compare a model variance with a residual variance. $\mathrm{F}$ value was calculated from a model mean square divided by residual mean square value. If $\mathrm{f}$ value was approaching to one means both variances were same, according $\mathrm{F}$ value highest was best to find critical input parameter.

Table 5 ANOVA result for vol. shrinkage

\begin{tabular}{|l|c|c|c|c|c|}
\hline \multicolumn{1}{|c|}{ Source } & DF & Adj SS & Adj MS & F-Valve & P-Value \\
\hline Regression & 5 & 0.258166 & 0.051633 & 7.05 & 0.001 \\
\hline Melt temp. & 1 & 0.007240 & 0.007240 & 0.99 & 0.331 \\
\hline Mold temp. & 1 & 0.082283 & 0.082283 & 11.23 & 0.003 \\
\hline Packing Pr. & 1 & 0.000636 & 0.000636 & 0.09 & 0.771 \\
\hline Sprue dia. & 1 & 0.150335 & 0.150335 & 20.52 & 0.000 \\
\hline Gate dia. & 1 & 0.017672 & 0.017672 & 2.41 & 0.135 \\
\hline Error & 21 & 0.153853 & 0.007326 & & \\
\hline Total & 26 & 0.412018 & & & \\
\hline
\end{tabular}

Table 6 ANOVA result for fill time

\begin{tabular}{|l|c|c|c|c|c|}
\hline \multicolumn{1}{|c|}{ Source } & DF & Adj SS & Adjacent MS & F-Valve & P-Value \\
\hline Regression & 5 & 0.148854 & 0.029771 & 12.65 & 0.00 \\
\hline Melt temp. & 1 & 0.055223 & 0.055223 & 23.46 & 0.000 \\
\hline Mold temp. & 1 & 0.002544 & 0.002544 & 1.08 & 0.310 \\
\hline Packing Pr. & 1 & 0.001318 & 0.001318 & 0.56 & 0.463 \\
\hline Sprue dia. & 1 & 0.082689 & 0.082689 & 35.13 & 0.000 \\
\hline Gate dia. & 1 & 0.007081 & 0.007081 & 3.01 & 0.098 \\
\hline Error & 21 & 0.049436 & 0.002354 & & \\
\hline Total & 26 & 0.198290 & & & \\
& & & & & \\
\hline
\end{tabular}

From the literature review it was found that if any term have a very small ' $\mathrm{P}$ ' value (less than 0.05 ) then it shows a significant effect on the responses in the regression modal.

Table 5 to table 6 list out that $\mathrm{F}$ value for regression models were very high (table 4 ' $\mathrm{F}$ ' value was 20.52, table $5^{\circ} \mathrm{F}$ 'value was 35.13 ) than 1 and $\mathrm{P}$ value were very less (approx 0.0000) suggested that all cases were significant.

\subsection{Model Equations:}




\subsubsection{Fill Time:Regression Equation}

Fill Time $=\quad 2.810-0.01108$ Melt Temp. +0.00238 Mold Temp.+0.00171

Packing Pr. + 0.03389 Sprue Dia. + 0.0198 Gate Dia.

\subsubsection{Regression Equation for Shrinkage}

Vol. shrinkage $(\%)=6.45-0.00401$ Melt Temp. +0.01352 Mold Temp. +0.00119

Packing Pr. + 0.0457 sprue Dia. + 0.0313 Gate Dia

\subsubsection{Normal Probability Graphs}

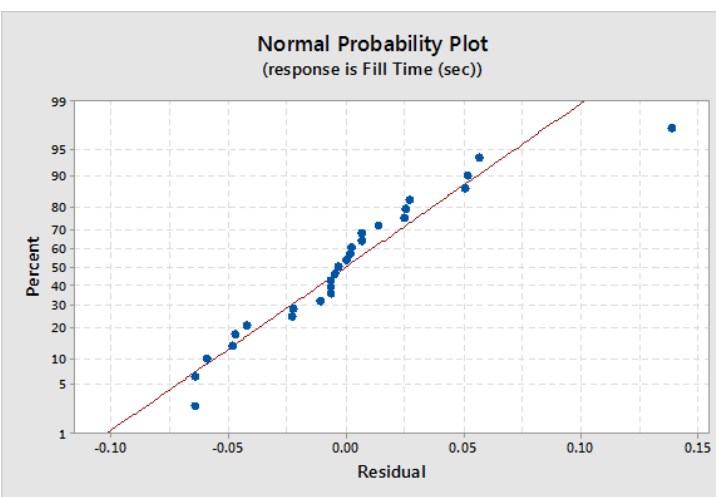

(a) Fill time

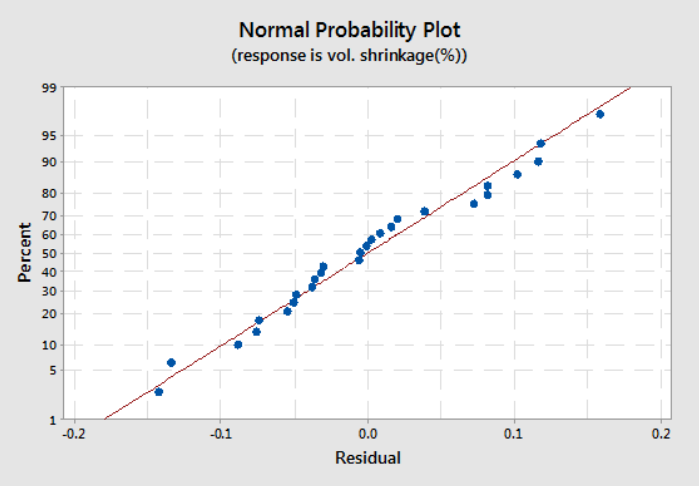

(b) Shrinkage

Fig. 7 Normal Probability Graphs for Fill time and shrinkage

\section{Contours of Fill Time}

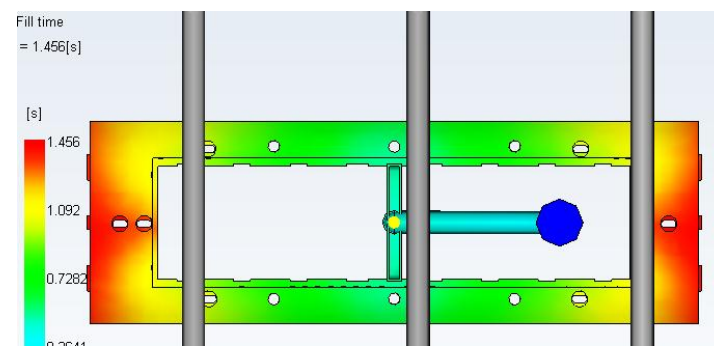

Fig. 8 Experiment 1 (Fill Time)

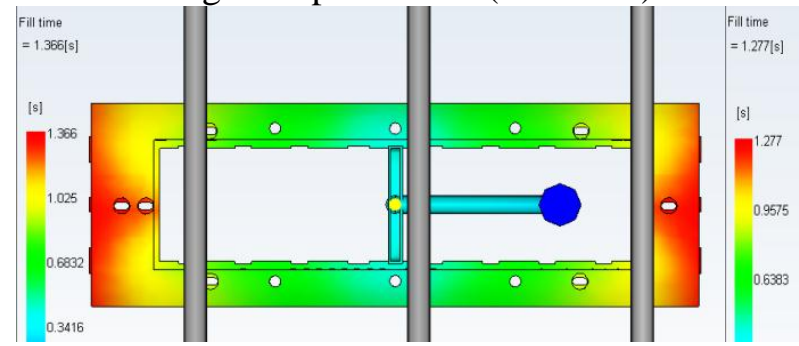

Fig. 10 Experiment 18 (Fill Time)

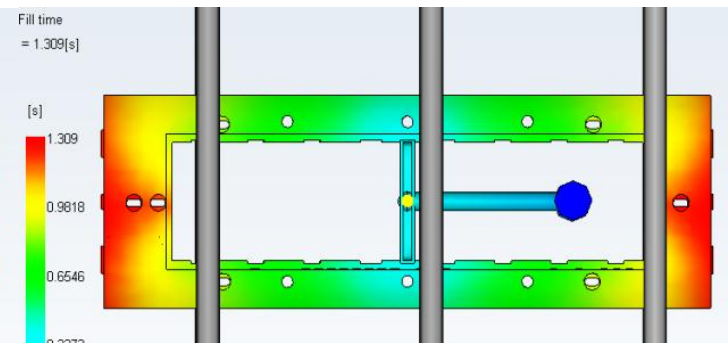

Fig. 9 Experiment 9 (Fill Time)

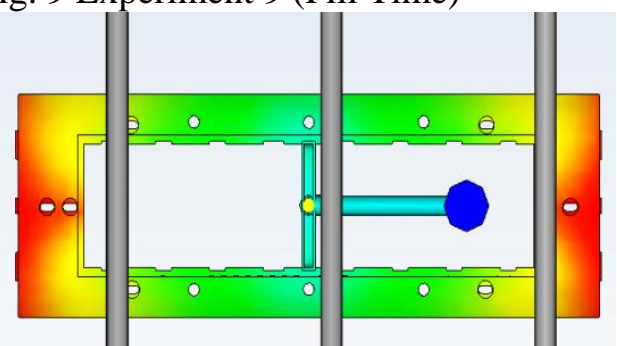

Fig. 11 Experiment 27 (Fill Time) 


\section{Contours of Volumetric Shrinkages}

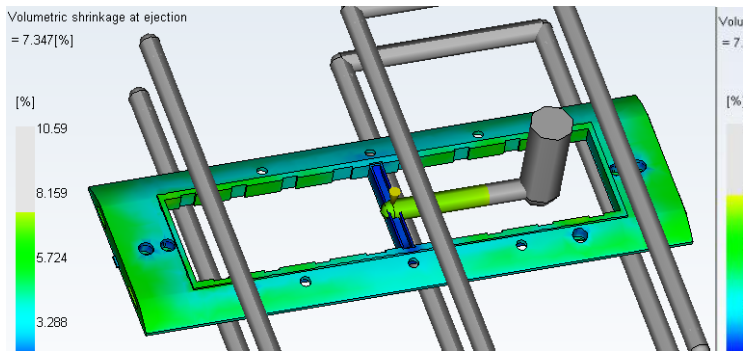

Fig. 12 Experiment 1 (vol. shrinkage)

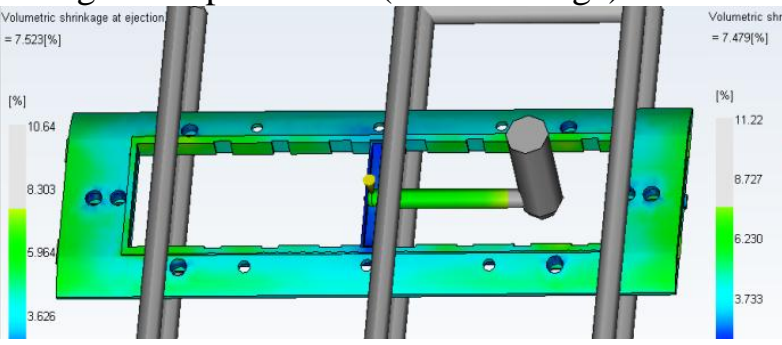

Fig. 14 Experiment 18 (vol. shrinkage)

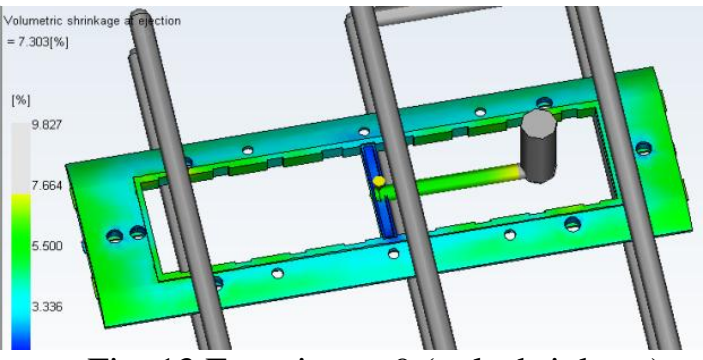

Fig. 13 Experiment 9 (vol. shrinkage)

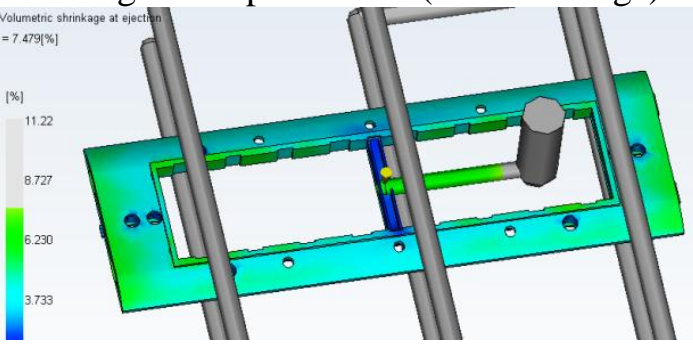

Fig. 15 Experiment 27 (vol. shrinkage)

\section{CONCLusion}

The aim of this study is to strike balance among response efficiency and FEM simulation results for mold flow plastic injection process. This study utilizes L27 orthogonal array for data analysis for plastic product. In this study Analysis of variance (ANOVA), and regression analysis was used as a main techniques to explain response and factor relations strongly with each other. Main results are summarized as follows:

\section{Best case for this study}

Best Case: A3-B1-C1-D1-E1 (235- 45- 90- 16- 8)

ANOVA results indicate that the sprue diameter and mold temperature were most significant factors for volumetric shrinkage for product. Like that for fill time melt temperature and spure diameter were most critical factors for product. Model equations for fill time and shrinkage was predict accurately with Minitab software and show $90 \%$ good prediction for responses and can be used by any plastic injection molding process manufacturer. 


\section{Contour of Best Case}

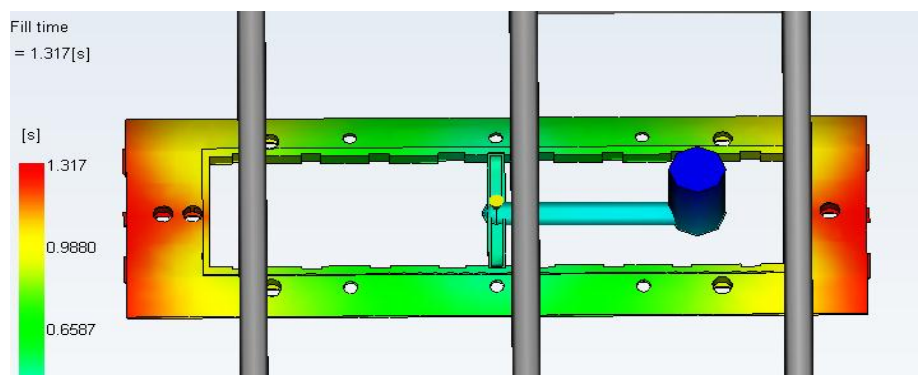

Fig.16 Fill time

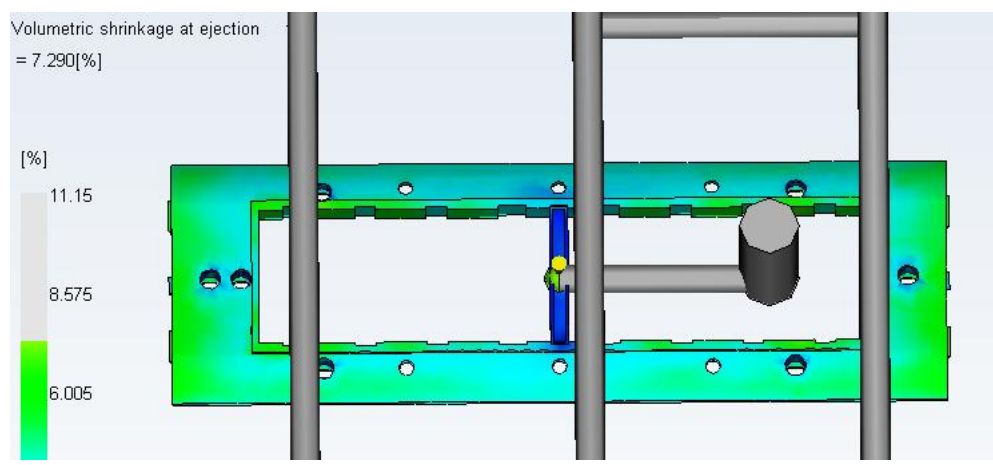

Fig.17 Vol. Shrinkage

\section{REFERENCES}

[1] Pye RGW. Injection Mould Design. Harlow (Longman Scientific \&Technical);1989. p. 358.

[2] Tor SB, Loh NH, Khor KA, Yoshida H. The effects of gate size in powder injection molding. Mater Manuf Processes 1997;12(4):629-40.

[3] Shen YK, Wu CW, Yuc YF, Chungc HW. Analysis for optimal gate design of thinwalled injection molding. IntCommun Heat Mass Trans 2008;35(6):728-34.

[4] Xie L, Ziegmann G. Effect of gate dimension on micro injection molded weld line strength with polypropylene (PP) and high-density polyethylene (HDPE). Int J AdvManufTechnol 2010;48(14):71-81.

[5] Xie PC, Du B, Yan ZY, Ding YM, Yang WM. Visual experiment study on the influence of mold structure design on injection molding product's defects. Adv. Mater Res 2010;87-88:31-5.

[6] Yokoi H. Recent development of visualization analysis techniques in injection molding. Denso Tech Rev 2006;11(2):3-13.

[7] Yokoi H, Masuda N, Mitsuhata H. Visualization analysis of flow front behavior during filling process of injection mold cavity by two-axis tracking system. JMater Process Technol 2002;130-131:328-33. 


\section{Authors}

Varun Sharma M.Tech. (Manufacturing Engineering) Manipal Univ Area of interest is plastic injection molding to improvement of product quality. E-mail address: varunsharma9925@gmail.com

Sanjay Kumar Sharma M.Tech. (Thermal Engineering) RTU, Kota Managing Director,Grob Design Pvt. Ltd., JaipurArea of interest is thermal efficiency improvement of heat exchangers, CFD use in Solar applications, Plastic Injection Molding, Building energy simulationE-mail address: sanjaybagra84@gmail.com

Vikas SharmaM.Tech. (Energy Engineering) MNIT, Jaipur Design Engineer, Grob Design Pvt. Ltd., JaipurHis area of interest is use of CFD in buildings, solarthermal devices and building energy simulation. E-mail ID: vikasmeche@gmail.com
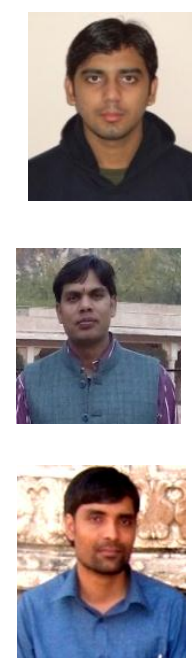

Ashish GoyalAsst. Professor, Manipal University, Jaipur (Raj.)His area of interest is use of CFD in buildings, Manufacturing Technique and PIM Process.E-mail ID: ashish.goyal@jaipur.manipal.edu

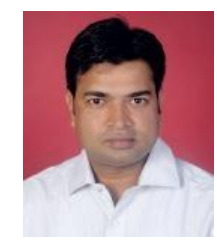

